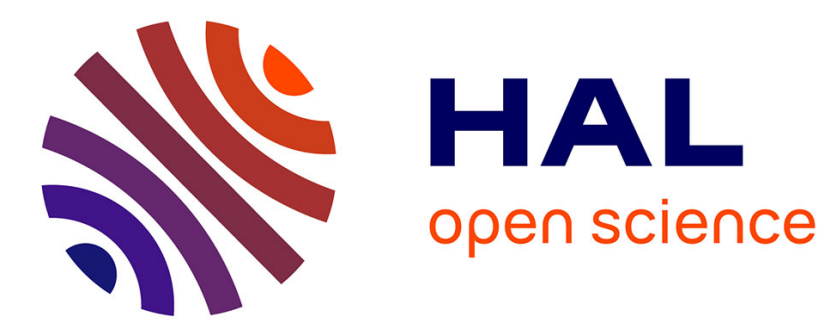

\title{
Compositional dependence of the optical properties of novel Ga-Sb-S-XI (XI = PbI2, CsI, AgI) infrared chalcogenide glasses
}

X. Huang, Q. Jiao, C. Lin, T. Xu, Hongli Ma, Xianghua Zhang, S. Dai

\section{- To cite this version:}

X. Huang, Q. Jiao, C. Lin, T. Xu, Hongli Ma, et al.. Compositional dependence of the optical properties of novel Ga-Sb-S-XI (XI = PbI2, CsI, AgI) infrared chalcogenide glasses. Journal of the American Ceramic Society, 2018, 101 (2), pp.749-755. 10.1111/jace.15238 . hal-01671625

HAL Id: hal-01671625

https://hal-univ-rennes1.archives-ouvertes.fr/hal-01671625

Submitted on 16 Mar 2018

HAL is a multi-disciplinary open access archive for the deposit and dissemination of scientific research documents, whether they are published or not. The documents may come from teaching and research institutions in France or abroad, or from public or private research centers.
L'archive ouverte pluridisciplinaire HAL, est destinée au dépôt et à la diffusion de documents scientifiques de niveau recherche, publiés ou non, émanant des établissements d'enseignement et de recherche français ou étrangers, des laboratoires publics ou privés. 
DR QING JIAO (Orcid ID : 0000-0003-1482-6981)

Article type : Article

Contributing editor: Pierre Lucas

Compositional Dependence of the Optical Properties of Novel Ga-Sb-S-XI (XI=PbI, CsI, AgI) Infrared Chalcogenide Glasses

\section{Xinyu Huang ${ }^{1} \mid$ Qing Jiao $^{1 *} \mid$ Changgui Lin $^{1} \mid$ Tiefeng Xu ${ }^{1 *} \mid$ Hongli Ma $^{2} \mid$ Xianghua $^{2}$ Zhang $^{2}$ | Shixun Dai ${ }^{1}$}

${ }^{1}$ Key Laboratory of Photoelectric Detection Materials and Devices of Zhejiang Province, Ningbo University, 315211, Ningbo, China

${ }^{2}$ Laboratory of Glasses and Ceramics, Institute of Chemical Science UMR CNRS 6226, University of Rennes 1, 35042, Rennes, France

*Author to whom correspondence should be addressed. e-mail: jiaoqing@ nbu.edu.cn; xutiefeng@nbu.edu.cn.

This article has been accepted for publication and undergone full peer review but has not been through the copyediting, typesetting, pagination and proofreading process, which may lead to differences between this version and the Version of Record. Please cite this article as doi: $10.1111 /$ jace. 15238

This article is protected by copyright. All rights reserved. 


\section{Abstract}

A novel family of $\mathrm{Ga}_{2} \mathrm{~S}_{3}-\mathrm{Sb}_{2} \mathrm{~S}_{3}-\mathrm{XI}$ (XI= $\mathrm{PbI}_{2}, \mathrm{CsI}, \mathrm{AgI}$ ) was investigated to understand the role of metal halides and exploit new chalco-halide glasses for infrared optics. The dependence of the thermal properties, infrared optical properties, and structural information of the novel family on different metal-iodines was investigated. Results showed that metal halides increase the glass stability but decrease the glass network connectivity. The compositional dependence of the short-wave cut-off edge is associated with the electronegativity difference between the cations and anions of the metal halides. Raman study showed that the metal-iodine modified the glass structure mainly through the iodide content, and the cations dissolved in the glass network mostly as charge compensators for the aperiodic network. For the glasses in the series $\mathrm{Ga}_{2} \mathrm{~S}_{3}-\mathrm{Sb}_{2} \mathrm{~S}_{3}-\mathrm{XI}-\mathrm{Dy}^{3+}$, $\mathrm{Dy}^{3+}$ emission increased in the $\mathrm{PbI}_{2}$ - and CsI-doped glasses but decreased in the AgI-doped glass due to the combined effect of dysprosium and oxygen. For all that, these novel glasses are highly promised for use in infrared optics.

\section{1 | INTRODUCTION}

Chalcogenide glasses and halide glasses are famous as infrared optical materials and have received great interest in their passive applications for few years. ${ }^{1-3}$ These glasses also possess low phonon energies, low multiphonon relaxation tendency, and large third-order nonlinear susceptibility $\chi^{(3)}$ which can be used in integrated optoelectronic devices. As such, the glasses have recently attracted increased attention to their active applications, such as laser hosts and nonlinear optical devices. ${ }^{4,5}$ However, some imminent defects of This article is protected by copyright. All rights reserved. 
chalcogenide and halide glasses limit their practical applications. Chalcogenide glasses present relatively good chemical and thermal stabilities, as well as high glass transition temperatures, which allow high working temperatures. Even so, the mechanical properties are generally poor. ${ }^{6}$ Meanwhile, halide glasses involve low optical loss and require low glass transition temperatures but suffer from poor chemical stability and high crystallization tendency. ${ }^{7}$ Therefore, preparing chalcohalide glass was proposed to overcome the shortcomings of both components while retaining the above-mentioned advantages. Several studies suggest that introducing elemental halogen (of low melting temperature and large polarizability) into chalcogenide glass can increase the glass packing density, avoid glass devitrification, and thus greatly improve the glass-forming ability. ${ }^{8,9}$ Among these chalcogenide systems, glasses from the Ge- or As-based glasses are most investigated in terms of their structural relationship with added metal halides. ${ }^{10-13}$ The iodide and metals in metal-iodines, such as $\mathrm{PbI}_{2}, \mathrm{AgI}$, and CsI, are both highly polarizable elements. Thus, metal-iodines can obtain a high second-order or third-order nonlinearity. ${ }^{14}$ Recently, a novel chalcogenide glass system Ga-Sb-S was developed by Zhang et al. ${ }^{15-17}$ This glass system exhibits a much lower phonon energy than those of Ge- or As-based glasses. ${ }^{17}$ Nevertheless, no work has comprehensively studied the influence of metal halides on the structure and properties of $\mathrm{Ga}-\mathrm{Sb}-\mathrm{S}$ chalcogenide glasses.

In the present study, the novel glass systems of $\mathrm{Ga}-\mathrm{Sb}-\mathrm{S}-\mathrm{XI}\left(\mathrm{XI}=\mathrm{PbI}_{2}, \mathrm{CsI}, \mathrm{AgI}\right)$ were prepared, and the compositional dependence of the optical properties of the glass systems was assessed. Given the investigation of the thermal stability, absorption spectra, and infrared spectra of the glass system, the optic effects of metal-iodine on the $\mathrm{Ga}-\mathrm{Sb}-\mathrm{S}$ glasses were This article is protected by copyright. All rights reserved. 
discussed systematically. Moreover, considering the metal halide effect on the existing chalcogenide glass systems, this work offers additional candidate materials for infrared applications.

\section{2 | EXPERIMENTAL PROCEDURE}

Bulk glasses of the nominal compositions $20 \mathrm{Ga}_{2} \mathrm{~S}_{3}-80 \mathrm{Sb}_{2} \mathrm{~S}_{3}$ (GSS), $\left(20 \mathrm{Ga}_{2} \mathrm{~S}_{3}-80 \mathrm{Sb}_{2} \mathrm{~S}_{3}\right)_{0.8}(\mathrm{XI})_{0.2}\left(\mathrm{XI}=\mathrm{PbI}_{2}, \mathrm{CsI}, \mathrm{AgI}\right.$, denoted as GP, GC, and GA respectively) and $\left(20 \mathrm{Ga}_{2} \mathrm{~S}_{3}-80 \mathrm{Sb}_{2} \mathrm{~S}_{3}\right)_{0.8}(\mathrm{XI})_{0.2}-0.1 \mathrm{wt} \% \mathrm{Dy}^{3+}\left(\mathrm{XI}=\mathrm{PbI}_{2}, \mathrm{CsI}, \mathrm{AgI}\right)$ were prepared in a silica tube under vacuum $\left(10^{-5} \mathrm{mbar}\right)$. In this process, high-purity raw materials $\mathrm{Ga}, \mathrm{Sb}, \mathrm{S}$ (99.999\%), CsI, $\mathrm{AgI}, \mathrm{PbI}_{2}$, and $\mathrm{Dy}_{2} \mathrm{~S}_{3}(99.99 \%)$ were used. The starting materials were placed in the same silica tube, which was then sealed under vacuum to give a silica ampule of 10 $\mathrm{mm}$ diameter and $10 \mathrm{~cm}$ length where the glass batch was melted. For melting, the ampule was placed in a tipping furnace and progressively heated from room temperature to the refining temperature of $850{ }^{\circ} \mathrm{C}$ at the heating rate of $1.5^{\circ} \mathrm{C} / \mathrm{min}$. The melt was homogenized at $850{ }^{\circ} \mathrm{C}$ for $16 \mathrm{~h}$, slowly cooled at $650{ }^{\circ} \mathrm{C}$, and maintained at this temperature for $2 \mathrm{~h}$ to obtain the vapor condensation present in the ampule. The batch was quenched in water to allow glass formation and avoid crystallization. Afterward, the vitreous sample was annealed at $20{ }^{\circ} \mathrm{C}$ below its glass transition temperature for $5 \mathrm{~h}$ to relax the internal mechanical stress induced by the quenching process. Finally, the annealed glasses were sliced $(\Phi 10 \mathrm{~mm} \times 2 \mathrm{~mm})$ and then polished to mirror smoothness.

This article is protected by copyright. All rights reserved. 
The samples were analyzed by X-ray diffraction (XRD) to confirm the glassy state. XRD measurements of the powder sample were performed using a Germany Bruker D2 diffractometer. The diffraction patterns were scanned over the $2 \theta$ range of $10^{\circ}-70^{\circ}$ in $0.1^{\circ}$ steps. The glass temperature $\left(\mathrm{T}_{\mathrm{g}}\right)$ and crystallization temperature $\left(\mathrm{T}_{\mathrm{x}}\right)$ were measured for the different samples by using a TA Instrument differential scanning calorimeter (DSC Q2000) at the heating rate of $10{ }^{\circ} \mathrm{C} / \mathrm{min}$ between room temperature and $400{ }^{\circ} \mathrm{C}$. The error of the characteristic temperatures was about $\pm 1^{\circ} \mathrm{C}$. A Perkin-Elmer Lambda 950 UV/VIS/NIR spectrophotometer was used to analyze the Vis-NIR transmission spectra of the glass samples. Meanwhile, a Nicolet 380 Fourier IR spectrophotometer was employed obtain the infrared transmission spectra within the range of $2-16 \mu \mathrm{m}$. The PL in the infrared region was measured using an FLS 980 fluorescence spectrometer with an 808-nm laser diode excitation.

\section{3 | RESULTS AND DISCUSSION}

In this study, $20 \mathrm{~mol} \% \mathrm{PbI}_{2}, \mathrm{CsI}$, and $\mathrm{AgI}$ were introduced into the $\mathrm{Ga}-\mathrm{Sb}-\mathrm{S}$ glass system.

Owing to the prepared glasses are black and opaque in the visible region, they could not be visually examined. XRD was hence used to determine the amorphous state of glasses. No distinct peak corresponding to any crystalline phase can be seen in the diffraction patterns (Figure 1) indicating that all the samples keep the amorphous state. In addition, the small halos at the low diffraction angle in the diffractograms of the bulk materials are due to the polymeric nature of the materials, corresponding to $S$ related polymeric rings. The size of this halo is affected by factors such as the preparation technique, mixing in the bulk material, etc.

This article is protected by copyright. All rights reserved. 
Figure 2 shows the DSC curves for the glass samples, whereas Table I summarizes important macroscopic data, such as the $\mathrm{T}_{\mathrm{g}}$ and the $\mathrm{T}_{\mathrm{x}}$. The metal-iodine addition into the GSS base glass considerably decreased the $T_{g}$. $T_{g}$ is usually associated with the degree of glass network cross-linking. ${ }^{18}$ Hence, adding the network terminating atom I, which is a nonbridging atom (unlike the bridging sulfur atoms), decreases the glass network connectivity and opens the glass network further. Therefore, the $\mathrm{T}_{\mathrm{g}}$ decreases with iodine addition. Actually, iodide has been reported to dissociate glass networks in other chalcogenide glasses. ${ }^{8,10,19}$ The criterion $\Delta \mathrm{T}$ (difference between $\mathrm{T}_{\mathrm{x}}$ and $\mathrm{T}_{\mathrm{g}}$ ) is known as a critical parameter evaluating the thermal stability and fiber-drawing ability of a glass. Glass with $\Delta \mathrm{T}>100{ }^{\circ} \mathrm{C}$ could generally be drawn into fibers. The glasses in this system possess $\Delta \mathrm{T}$ higher than $100{ }^{\circ} \mathrm{C}$ thus show potential application in being drawn as fibers. Moreover, the thermal stability criterion of $\mathrm{H}_{\mathrm{w}}=\Delta \mathrm{T} / \mathrm{T}_{\mathrm{g}}$ is also used to evaluate the thermal stability of these glasses. ${ }^{20}$ Table I reveals that the thermal stability of the glasses can be effectively enhanced by adding metal halides. Generally, introducing iodide into the GSS glass progressively breaks $\mathrm{Ga}-\mathrm{S}$ bonds forming $\left[\mathrm{GaS}_{4}\right]$ or $\left[\mathrm{GaS}_{4-\mathrm{x}} \mathrm{I}_{\mathrm{x}}\right]$ tetrahedra; the formation of this complex tetrahedral is assumed to favor glass formation. The iodide content for the GP is the highest; hence, the GP contains the most number of $\left[\mathrm{GaS}_{4}\right]$ or $\left[\mathrm{GaS}_{4-\mathrm{x}} \mathrm{I}_{\mathrm{x}}\right]$ tetrahedral structural units (s.u.) among these glasses. This result also implies that the thermal stability against devitrification for GP is considerably high. However, the structures of the studied glasses must first be analyzed to confirm the above-mentioned findings.

This article is protected by copyright. All rights reserved. 
The Vis-NIR transmission spectra for the glasses containing different metal-iodines are presented in the $600-850 \mathrm{~nm}$ region (Figure 3 ) and reveal the dependence of the short-wave cut-off edge $\left(\lambda_{\text {vis }}\right)$ on the harbored metal halide. In particular, the $\lambda_{\text {vis }}$ shifts to a shorter wavelength when the metal halide was CsI, but to a longer wavelength for AgI. By contrast, the $\lambda_{\text {vis }}$ is nearly constant for $\mathrm{PbI}_{2}$ in the pseudo-ternary $\mathrm{Ga}-\mathrm{Sb}-\mathrm{S}$ glass system. This observation is consistent with the relation of the glasses' short-wave absorption edge to the electrical transition between the valence band and conduction band. Therefore, adding anions I with similar electronegativities but larger ionic radii than that of sulfur can lead to $\lambda_{\text {vis }}$ blue shift due to band gap broadening caused by the large ionic radius. By contrast, addition of cations with high polarizability can lead to $\lambda_{\text {vis }}$ red shifts. Given these two factors, the $\lambda_{\text {vis }}$ pattern of the chalco-halide glasses cannot be explained clearly. Herein, the electronegativity difference of the anions and cations is introduced to clarify the phenomenon. In a previous work of F. Di Quarto et al., ${ }^{21}$ optical band gap values were positively correlated with the electronegativity difference between anion and cation in the traditional Pauling's scale. The electronegativity differences of $\mathrm{Pb}-\mathrm{I}, \mathrm{Ag}-\mathrm{I}$, and $\mathrm{Cs}-\mathrm{I}$ are $0.33,0.73$, and 1.87 , respectively. The electronegativities of the $\mathrm{Pb}$ and $\mathrm{Ag}$ ions are close to that of I and result in a small difference between the cations and anions. For the CsI-modified sample, the electronegativity difference of I and Cs is large. Given the above-mentioned argument, we understand that the red shift effect of $\mathrm{Pb}$ and $\mathrm{Ag}$ in samples is more pronounced than that of $\mathrm{Cs}$.

The optical band gap $\mathrm{E}_{\mathrm{opt}}$ is obtained by extrapolating the linear portion of the curve to the photon energy h $\omega$ axis. Figure 4 also depicts the plots of $(\alpha(\omega) h \omega)^{1 / 2}$ and $(\alpha(\omega) h \omega)^{2}$ as functions of hw in $\mathrm{eV}$ for directly allowed and indirectly allowed transitions. The measured This article is protected by copyright. All rights reserved. 
indirect optical band gaps of the glass system are 1.6846 (GA), 1.7374 (GP), 1.7535 (GSS), 1.8389 (GC), respectively, the direct optical band are 1.7714 (GA), $1.8070(\mathrm{GP}), 1.8172$ (GSS), 1.9082 (GC), respectively. The variations in the direct and indirect optical band gaps coincide with the influence of the metal-iodine on the Vis-NIR transmission spectra. In the chalcogenide glasses, the valence band is composed of lone pair electrons, whereas the conduction band is composed of empty orbits. Adding low-electronegativity atoms into the glass matrix increases the energy of the lone pair electrons and in turn expands the valence band width. ${ }^{22}$ Therefore, adding the highly electronegative I and low-polarizability $\mathrm{Cs}^{+}$in the glass network broadens the width of the forbidden band and consequently increases the optical band gap. ${ }^{19}$ For the $\mathrm{PbI}_{2}$-modified sample, the loose electronic shell and $6 \mathrm{~s}^{2}$ outermost electron attain a relatively large UV-cutoff edge, which then decreases the optical band gap, ${ }^{14}$ while the highly electronegative anion I broaden the band gap, these two factors resulted in the formation of an almost constant optical band gap. By contrast, the average bond strength of the compound decreases substantially in the AgI-doped sample when the Sb-S, Ga-S, and S-S bonds were replaced by the lower-energy Ag-S bond. ${ }^{23}$ This effect suggests that the decrease in average bond strength of the compound decreases the average gap. Hence, increasing the $\mathrm{Ag}-\mathrm{S}$ content weakens the bond strength and reduces the optical band.

As infrared-transmitting materials, the prepared glasses were analyzed for their optical transmission spectra (Figure 5). With metal halide addition, the transparency region maintained a good transmission from $2.5 \mu \mathrm{m}$ to the multiphonon processes at $14 \mu \mathrm{m}$. Thus, the glasses possess optical properties suitable for infrared transmission. With compositional changes, the transmission percentages increased for $\mathrm{AgI}$ and $\mathrm{PbI}_{2}$, but decreased for CsI, in This article is protected by copyright. All rights reserved. 
the pseudo-ternary $\mathrm{Ga}-\mathrm{Sb}-\mathrm{S}$ glass system. The absorption band at about $4.10 \mu \mathrm{m}$, which is the strongest spectral peak, is assigned to $\mathrm{S}-\mathrm{H}$ vibrations. The minor absorption bands at about 2.92-3.25 $\mu \mathrm{m}$ are assigned to the stretch modes of $\mathrm{OH}$ hydroxyl groups, whereas that at $6.31 \mu \mathrm{m}$ is assigned to $\mathrm{H}_{2} \mathrm{O}$ molecular vibration. Meanwhile, the band at $9.71 \mu \mathrm{m}$ belongs to $\mathrm{Sb}-\mathrm{O}$ bond vibration. ${ }^{24}$ These impurities originate from the surface oxidation of raw elements and the hydroxide contamination during glass preparation. The impurity absorption bands strengthen with $\mathrm{AgI}$ addition under $-\mathrm{OH}$ and $\mathrm{S}-\mathrm{H}$ absorption because of the hygroscopic property. ${ }^{25}$ Heavy-metal halides are generally more stable against oxidation than $\mathrm{Sb}, \mathrm{Ga}$, and $\mathrm{S}$. Thus, the absorption band of $\mathrm{Sb}-\mathrm{O}$ is strong in the $\mathrm{GA}$ for the glass containing numerous oxygen atoms. Purification technology $y^{26,27}$ is necessary to eliminate the impurities that would influence infrared optical material applications, such as thermal imaging.

To study the effect of different metal-iodines on the structure of GSS glass, the reduced Raman spectra of the metal-iodines doped glasses and base glass are investigated, these spectra are then deconvoluted into a series of Gaussian sub-bands as shown in Figure 6. The assignments of Raman shift of GSS glass are summarized in Table 2. Meanwhile, in the GSS glass, given the formation of $\left[\mathrm{GaS}_{4}\right]$ tetrahedra $(\mathrm{S} / \mathrm{Ga}=2),\left[\mathrm{S}_{3} \mathrm{Ga}-\mathrm{GaS}_{3}\right]$ ethane-like units (s.u.) $(\mathrm{S} / \mathrm{Ga}=2 / 3)$ were mainly formed instead of $\left[\mathrm{GaS}_{4}\right]$ tetrahedra to alleviate the shortage of sulfur atoms.

When CsI, AgI, and $\mathrm{PbI}_{2}$ were added, the Raman vibrations were modified. As shown in the Figure 6, firstly, owing to the Ga-I bond would preferentially form compared with Ga-S, the Ga-Ga bond in the ethane-like subunits of $\left[\mathrm{S}_{3} \mathrm{Ga}-\mathrm{GaS}_{3}\right]$ is gradually converted into

This article is protected by copyright. All rights reserved. 
$\left[\mathrm{GaS}_{4-\mathrm{x}} \mathrm{I}_{\mathrm{x}}\right]$ mixed s.u. and lead to the peak at about $265 \mathrm{~cm}^{-1}$ shrink in intensity.

Theoretically, the Raman shift of $\left[\mathrm{GaS}_{4-\mathrm{x}} \mathrm{I}_{\mathrm{x}}\right]$ unit is lower than that of $\left[\mathrm{GaS}_{4}\right]$ unit according to the theory of molecular vibration. ${ }^{31}$ However, according to the research of H. Guo, ${ }^{32}$ the Raman shift of mixture $\left[\mathrm{GaS}_{4-\mathrm{x}} \mathrm{I}_{\mathrm{x}}\right]$ and $\left[\mathrm{GaS}_{4}\right]$ almost unchanged compared to that of single $\left[\mathrm{GaS}_{4}\right]$ structural unit which ascribed to $342 \mathrm{~cm}^{-1}$, this phenomenon is coincide with the reduced Raman spectra as shown in Figure 6. Thus, the Raman shift of $\left[\mathrm{GaS}_{4-\mathrm{x}} \mathrm{I}_{\mathrm{x}}\right]$ is almost the same with $\left[\mathrm{GaS}_{4}\right]$ unit at about $342 \mathrm{~cm}^{-1}$, and the formation of $\left[\mathrm{GaS}_{4-\mathrm{x}} \mathrm{I}_{\mathrm{x}}\right]$ unit enhanced the peak at about $342 \mathrm{~cm}^{-1}$ as shown in Figure 6. Secondly, for GP, its contains the most of iodide, the broad overlapping peak at $300 \mathrm{~cm}^{-1}$ shifts distinctly toward a higher wavenumber at about $308 \mathrm{~cm}^{-1}$ due to decreased peak at $265 \mathrm{~cm}^{-1}$ and increased peak at $342 \mathrm{~cm}^{-1}$. Finally, the Raman shift peak ascribed to $\mathrm{X}^{-}$is not found in Figure 6; this absence may be attributed to the dissolution of $\mathrm{Ag}^{+}, \mathrm{Cs}^{+}$, and $\mathrm{Pb}^{2+}$ in the glass network only as charge compensators for the aperiodic network. The interpretation of the $\mathrm{T}_{\mathrm{g}}$ results (Table 1) is also confirmed by the above analysis.

Given the low phonon energy of $\left[\mathrm{GaS}_{4-\mathrm{x}} \mathrm{I}_{\mathrm{x}}\right]$ and the beneficial properties of GSS-XI $\left(\mathrm{XI}=\mathrm{PbI}_{2}, \mathrm{AgI}, \mathrm{CsI}\right)$, the glass holds considerable potential as a RE-doped glassy matrix material that can emit NIR and mid-infrared (MIR) light. The luminescence characteristics of GSS-XI (XI=PbI 2, AgI, CsI) glasses were investigated. Figure 7(a) shows the emission spectra of $\mathrm{Dy}^{3+} /$ metal-iodine co-doped GSS glasses from $1200 \mathrm{~nm}$ to $3250 \mathrm{~nm}$, where the Dy $^{3+}$ doping content was $0.1 \mathrm{wt} \%$ upon $808 \mathrm{~nm}$ laser excitation. Three significant emission bands at $1.33,1.75$, and $2.88 \mu \mathrm{m}$ are displayed in the spectra. These emission bands can be assigned to the transitions $\left({ }^{6} \mathrm{H}_{9 / 2}+{ }^{6} \mathrm{~F}_{11 / 2}\right) \rightarrow{ }^{6} \mathrm{H}_{15 / 2},{ }^{6} \mathrm{H}_{11 / 2} \rightarrow{ }^{6} \mathrm{H}_{15 / 2}$, and ${ }^{6} \mathrm{H}_{13 / 2} \rightarrow{ }^{6} \mathrm{H}_{15 / 2}$, This article is protected by copyright. All rights reserved. 
respectively. Compared with GSS, much enhancement near infrared and MIR luminescence was realized for GP and GC, but the luminescence intensity decreased for GA. Given the above analysis, GA acquired a poorer connectivity and thermal stability than those of GC and GP and contained more oxygen atoms. In previous studies by Z. Tang ${ }^{33}$ and Y. Cheng, ${ }^{34}$ dysprosium was more electropositive than other elements in the chalcogenide formulation and tended to react with the oxide contamination in the glass melt to form dysprosium oxide. These oxides tend to be insoluble in the chalcogenide glass melt and may induce crystallization through the glass forming process and consequently reduce the emission intensity of $\mathrm{Ag}^{+} / \mathrm{Dy}^{3+}$ co-doped glass. The luminescence of GP is more enhanced than that of GC. Raman study showed that the content of $\left[\mathrm{GaS}_{4-\mathrm{x}} \mathrm{I}_{\mathrm{x}}\right]$ mixed tetrahedra-like s.u. increased with iodide concentration in the glass matrix. Apparently, the $\left[\mathrm{GaS}_{4-\mathrm{x}} \mathrm{I}_{\mathrm{x}}\right]$ mixed tetrahedra-like s.u. content followed the order of GSS $<\mathrm{GC}<\mathrm{GP}$. The $\left[\mathrm{GaS}_{4-\mathrm{x}} \mathrm{I}_{\mathrm{x}}\right]$ mixed tetrahedral-like s.u. also possess a lower phonon energy than that of the $\left[\mathrm{GaS}_{4}\right]$ s.u. and the lower phonon energy of $\left[\mathrm{GaS}_{4-\mathrm{x}} \mathrm{I}_{\mathrm{x}}\right]$ contribute the emission of $\mathrm{Dy}^{3+}$ ions. According to previous works, ${ }^{35,36}$ positively charged RE ions preferably rest in these sites as charge compensators and enhance the luminescence through reduced multiphonon relaxation. Thus, the luminescence intensity followed the order of GSS $<\mathrm{GC}<\mathrm{GP}$. Overall, $\mathrm{Dy}^{3+}$ emission is highly sensitive to the local chemical environment of the $\mathrm{Dy}^{3+}$ ions embedded in these metal-iodine-modified glasses.

This article is protected by copyright. All rights reserved. 


\section{4 | CONCLUSIONS}

In this paper, we report the evolution of novel chalco-halide glasses $\mathrm{Ga}_{2} \mathrm{~S}_{3}-\mathrm{Sb}_{2} \mathrm{~S}_{3}-\mathrm{XI}$ (XI= $\left.\mathrm{PbI}_{2}, \mathrm{CsI}, \mathrm{AgI}\right)$. Metal halide addition decreased the glass network connectivity and increased the thermal stability. The movement tendency of the short wavelength absorption edge was supposedly related to the electronegativity difference between cations and anions of metal halides. However, the cations of the metal-iodine only dissolved into the glass network as charge compensators for the aperiodic network, as revealed by Raman study. For the $\mathrm{Dy}^{3+}$-doped GP and GC, intense luminescence was realized for the iodide-modified glasses due to the dissociation of $\mathrm{Ga}-\mathrm{Ga}$ metal bonds convert into $\left[\mathrm{GaS}_{4-\mathrm{x}} \mathrm{I}_{\mathrm{x}}\right]$ mixed tetrahedra-like s.u. These latter units provide a lower phonon energy and better chemical environment for $\mathrm{Dy}^{3+}$. This study offered a comprehensive explanation of the role of metal halides in chalco-halide glass, which are confirmed as good candidates for use in lasers and higher-luminescence sources in the NIR and MIR regions.

\section{ACKNOWLEDGEMENTS}

This work was supported by National Science Foundation of China (NSFC) (Grant no. 61605093), General Scientific Research Project of Zhejiang Province (Grant no. Y201533345), The National Key Reaserch and Development Program of china (No.2016YFB0303802 and 2016YFB0303803), The Open Research Fund of Key Laboratory of Yunnan Provience (Grant no. 2016CX07, SKL-SPM-201511), and sponsored by K. C. Wong Magna Fund in Ningbo University.

This article is protected by copyright. All rights reserved. 


\section{REFERENCES}

1. Eggleton BJ, Luther-Davies B, Richardson K. Chalcogenide photonics. Nat Photonics.

2011;5:141-148.

2. Almeida, Rui M. Halide glasses for infrared fiber optics. Springer Science \& Business Media. 2012.

3. Zhang B, Yu Y, Zhai C, et al. High brightness 2.2-12 $\mu \mathrm{m}$ mid-infrared supercontinuum generation in a nontoxic chalcogenide step-index fiber. J Am Ceram Soc. 2016;99:2565-2568.

4. Petersen CR, Møller U, Kubat I, et al. Mid-infrared supercontinuum covering the 1.4-13.3 $\mu \mathrm{m}$ molecular fingerprint region using ultra-high NA chalcogenide step-index fibre. Nat Photonics. $2014 ; 8: 830-834$.

5. Qiao B, Dai S, Xu Y, et al. Third-order optical nonlinearities of chalcogenide glasses within Ge-Sn-Se ternary system at a mid-infrared window. Opt Mater Express. 2015;5:2359.

6. Yang Z, Chen W, Ma H, et al. Controlled crystallization of $\mathrm{GeSe}_{2}-\mathrm{Ga}_{2} \mathrm{Se}_{3}-\mathrm{CsI}$ chalcohalide glasses during molding. J Am Ceram Soc. 2008;91:2720-2723.

7. Yue J, Xue T, Huang F, et al. Thermally stable mid-infrared fluorotellurite glass with low $\mathrm{OH}$ content. J Non-Cryst Solids. 2015;408:1-6.

8. Tang G, Yang Z, Luo L, et al. Formation and properties of $\mathrm{GeSe}_{2}-\mathrm{Ga}_{2} \mathrm{Se}_{3}-\mathrm{PbI}_{2}$ novel chalcohalide glasses. J Am Ceram Soc. 2008;91:1686-1689.

9. Qiu J, Yang A, Zhang M, et al. $\mathrm{Ga}_{2} \mathrm{~S}_{3}-\mathrm{Sb}_{2} \mathrm{~S}_{3}$-CsI chalcohalide glasses for mid-infrared applications. $J$ Am Ceram Soc. 2017.

This article is protected by copyright. All rights reserved. 
10. Yang Z, Tang G, Luo L, et al. Glass formation and properties of $\mathrm{GeSe}_{2}-\mathrm{Ga}_{2} \mathrm{Se}_{3}-\mathrm{MX}$ (MX is alkali halide) chalcohalide glasses. Mater Res Bull. 2008;43:3596-3600.

11. Khaoulani S, Kassem M, Fourmentin S, et al. The AgI-HgS- $\mathrm{As}_{2} \mathrm{~S}_{3}$ glassy system: Macroscopic properties and Raman scattering studies. J Alloys Compd. 2016;685:752-760.

12. Lin C, Calvez L, Li Z, et al. Enhanced up-conversion luminescence in $\mathrm{Er}^{3+}$-doped $25 \mathrm{GeS}_{2} \cdot 35 \mathrm{Ga}_{2} \mathrm{~S}_{3} \cdot 40 \mathrm{CsCl}$ chalcogenide glass-ceramics. J Am Ceram Soc. 2013;96:816-819.

13. Ma HL, Guimond Y, Zhang XH, et al. Ga-Ge-Sb-Se based glasses and influence of alkali halide addition. J Non-Cryst Solids. 1999; 257:165-169.

14. Guo $\mathrm{H}$, Zhai $\mathrm{Y}$, Tao $\mathrm{H}$, et al. Synthesis and properties of $\mathrm{GeS}_{2}-\mathrm{Ga}_{2} \mathrm{~S}_{3}-\mathrm{PbI}_{2}$ chalcohalide glasses. Mater Res Bull. 2007;42:1111-1118.

15. Yang A, Zhang M, Li L, et al. Ga-Sb-S chalcogenide glasses for mid-infrared applications. J Am Ceram Soc. 2016;99:12-15.

16. Jiao Q, Li G, Li L, et al. Effect of gallium environment on infrared emission in $\mathrm{Er}^{3+}$-doped galliumantimony- sulfur glasses. Sci Rep. 2017;7:41168.

17. Li G, Li L, Huang X, et al. $\mathrm{Er}^{3+}$ doped and $\mathrm{Er}^{3+} / \mathrm{Pr}^{3+}$ co-doped gallium-antimony-sulphur chalcogenide glasses for infrared applications. Optical Materials Express. 2016;6:3849-3856.

18. Zhang M, Yang Z, Li L, et al. The effects of germanium addition on properties of Ga-Sb-S chalcogenide glasses. J Non-Cryst Solids. 2016;452:114-118.

This article is protected by copyright. All rights reserved. 
19. Wang G, Nie Q, Barj M, et al. Compositional dependence of the optical properties of novel Ge-Ga-Te-CsI far infrared transmitting chalcohalide glasses system. J Phys Chem Solids. 2011;72:5-9.

20. Heo J, Park JK, Kim YS. Infrared transmitting Cd-As-Ge-I glasses. J Non-Cryst Solids. 1994;175:204-210.

21. Quarto FD, Sunseri C, Piazza S, et al. Semiempirical correlation between optical band gap values of oxides and the difference of electronegativity of the elements. $J$ Phys Chem B. 1997;101:2519-2525.

22. Li L, Li G, Zhang T, et al. Preparation and properties of $\mathrm{Ge}-\mathrm{Ga}-\mathrm{La}-\mathrm{S}-\mathrm{AgI}$ chalcogenide glass. Ceram Int. 2017;43:4508-4512.

23. Sanderson RT. Electronegativity and bond energy. J Am Chem Soc. 1983;105:2259-2261.

24. Snopatin GE, Shiryaev VS, Plotnichenko VG, et al. High-purity chalcogenide glasses for fiber optics. Inorg Mater. 2009;45:1439-1460.

25. Li Z, Lin C, Qu G, et al. Formation and properties of chalcogenide glasses based on $\mathrm{GeS}_{2}-\mathrm{Sb}_{2} \mathrm{~S}_{3}-\mathrm{AgI}$ system. Mater Lett. 2014;132:203-205.

26. Zhao Z, Wu B, Wang X, et al. Mid-infrared supercontinuum covering 2.0-16 $\mu \mathrm{m}$ in a low-loss telluride single-mode fiber. Laser Photonics Rev. 2017;11:1700005.

27. Kim WH, Nguyen VQ, Shaw LB, et al. Recent progress in chalcogenide fiber technology at NRL. $J$ Non-Cryst Solids. 2016;431:8-15.

This article is protected by copyright. All rights reserved. 
28. Ichikawa M, Wakasugi T, Kadono K. Glass formation, physico-chemical properties, and structure of glasses based on $\mathrm{Ga}_{2} \mathrm{~S}_{3}-\mathrm{GeS}_{2}-\mathrm{Sb}_{2} \mathrm{~S}_{3}$ system. J Non-Cryst Solids. 2010;356:2235-2240.

29. Heo J, Yoon JM, Ryoub SY. Raman spectroscopic analysis on the solubility mechanism of $\mathrm{La}^{3+}$ in $\mathrm{GeS}_{2}-\mathrm{Ga}_{2} \mathrm{~S}_{3}$ glasses. J Non-Cryst Solids. 1998;238:115-123.

30. Frumarováp B, Nemec P, Oswald J. Synthesis and properties of Ge-Sb-S:NdCl ${ }_{3}$ glasses. Semic. $1998 ; 32: 812-816$.

31. Dong G, Tao H, Xiao X, et al. Study on the third and second-order nonlinear optical properties of $\mathrm{GeS}_{2}-\mathrm{Ga}_{2} \mathrm{~S}_{3}-\mathrm{AgCl}$ chalcohalide glasses. Opt Express. 2007;15: 2398-2408.

32. Guo $\mathrm{H}$, Tao $\mathrm{H}$, Zhai $\mathrm{Y}$, et al. Raman spectroscopic analysis of $\mathrm{GeS}_{2}-\mathrm{Ga}_{2} \mathrm{~S}_{3}-\mathrm{PbI}_{2}$ chalcohalide glasses. Spectrochim Acta A. 2007;67:1351-1356.

33. Tang Z, Neate NC, Furniss D, et al. Crystallization behavior of Dy ${ }^{3+}$-doped selenide glasses. J Non-Cryst Solids. 2011;357:2453-2462.

34. Cheng Y, Tang Z, Neate NC, et al. The influence of dysprosium addition on the crystallization behavior of a chalcogenide selenide glass close to the fiber drawing temperature. J Am Ceram Soc. 2012;95:3834-3841.

35. Ren J, Wagner T, Bartos M, et al. Intense near-infrared and midinfrared luminescence from the $\mathrm{Dy}^{3+}$-doped $\mathrm{GeSe}_{2}-\mathrm{Ga}_{2} \mathrm{Se}_{3}-\mathrm{MI}(\mathrm{M}=\mathrm{K}, \mathrm{Cs}, \mathrm{Ag})$ chalcohalide glasses at 1.32, 1.73, and 2.67 $\mu \mathrm{m} . J \mathrm{Appl}$ Phys. 2011;109:1-5.

36. Xu Y, Chen D, Zhang Q, et al. Bright red upconversion luminescence of thulium ion-doped $\mathrm{GeS}_{2}$ - $\mathrm{In}_{2} \mathrm{~S}_{3}$-CsI glasses. J Phys Chem C. 2009;113:9911-9915.

This article is protected by copyright. All rights reserved. 


\section{Figure Captions}

Figure 1. XRD patterns of GSS glass and XI (XI=PbI $\left.{ }_{2}, \mathrm{CsI}, \mathrm{AgI}\right)$ doped GSS glasses.

Figure 2. DSC measurement of GSS glass and $\mathrm{XI}\left(\mathrm{XI}=\mathrm{PbI}_{2}, \mathrm{CsI}, \mathrm{AgI}\right)$ doped GSS glasses.

Figure 3. Vis-NIR transmission spectra for GSS glass and XI ( $\left.\mathrm{XI}=\mathrm{PbI}_{2}, \mathrm{CsI}, \mathrm{AgI}\right)$ doped GSS glasses.

Figure 4. Relationship between $(\alpha(\omega) h \omega)^{2},(\alpha \cdot h \omega)^{1 / 2}$ and h $\omega$ for glass samples.

Figure 5. Infrared transmission spectra of GSS glass and XI ( $\left.\mathrm{XI}=\mathrm{PbI}_{2}, \mathrm{CsI}, \mathrm{AgI}\right)$ doped GSS glasses.

Figure 6. Reduced Raman spectra of GSS glass and XI (XI=PbI 2 , CsI, AgI) doped GSS glasses.

Figure 7. (a) Emission spectra of GSS glass and XI (XI=PbI 2 , CsI, AgI) doped GSS glasses being pumped by $808 \mathrm{~nm}$. (b) Energy levels and transitions of $\mathrm{Dy}^{3+}$.

This article is protected by copyright. All rights reserved. 


\section{Table}

TABLE 1. Thermal parameters of glass samples.

\begin{tabular}{ccccc}
\hline Glass $\quad$ samples & $\mathbf{T}_{\mathbf{g}}\left({ }^{\circ} \mathrm{C}\right)$ & $\mathbf{T}_{\mathbf{x}}\left({ }^{\circ} \mathrm{C}\right)$ & $\mathbf{\Delta T}\left({ }^{\circ} \mathrm{C}\right)$ & $\mathbf{H}_{\mathbf{w}}$ \\
\hline GSS & 246.9 & 357.6 & 110.7 & 0.45 \\
$\mathrm{GC}$ & 232.8 & 363.2 & 130.4 & 0.56 \\
$\mathrm{GA}$ & 217.2 & 332.6 & 115.5 & 0.53 \\
$\mathrm{GP}$ & 219.5 & 405.3 & 185.8 & 0.85 \\
\hline
\end{tabular}

TABLE 2. Assignments of Raman shift of the GSS glass.

\begin{tabular}{lll}
\hline Raman shift $\left(\mathbf{c m}^{-\mathbf{1}}\right)$ & Assignments & Refs. \\
\hline $265 \mathrm{~cm}^{-1}$ & {$\left[\mathrm{~S}_{3} \mathrm{Ga}-\mathrm{GaS}_{3}\right]$} & 28 \\
& {$\left[\mathrm{SbS}_{3}\right]$ pyramids } & 15,28 \\
$290 \mathrm{~cm}^{-1}$ & {$\left[\mathrm{SbS}_{3}\right]$ pyramids } & 15,30 \\
$314 \mathrm{~cm}^{-1}$ & & $15,28,29$ \\
$342 \mathrm{~cm}^{-1}$ & Corner-sharing $\left[\mathrm{GaS}_{4}\right]$ tetrahedra & \\
\hline
\end{tabular}

This article is protected by copyright. All rights reserved. 

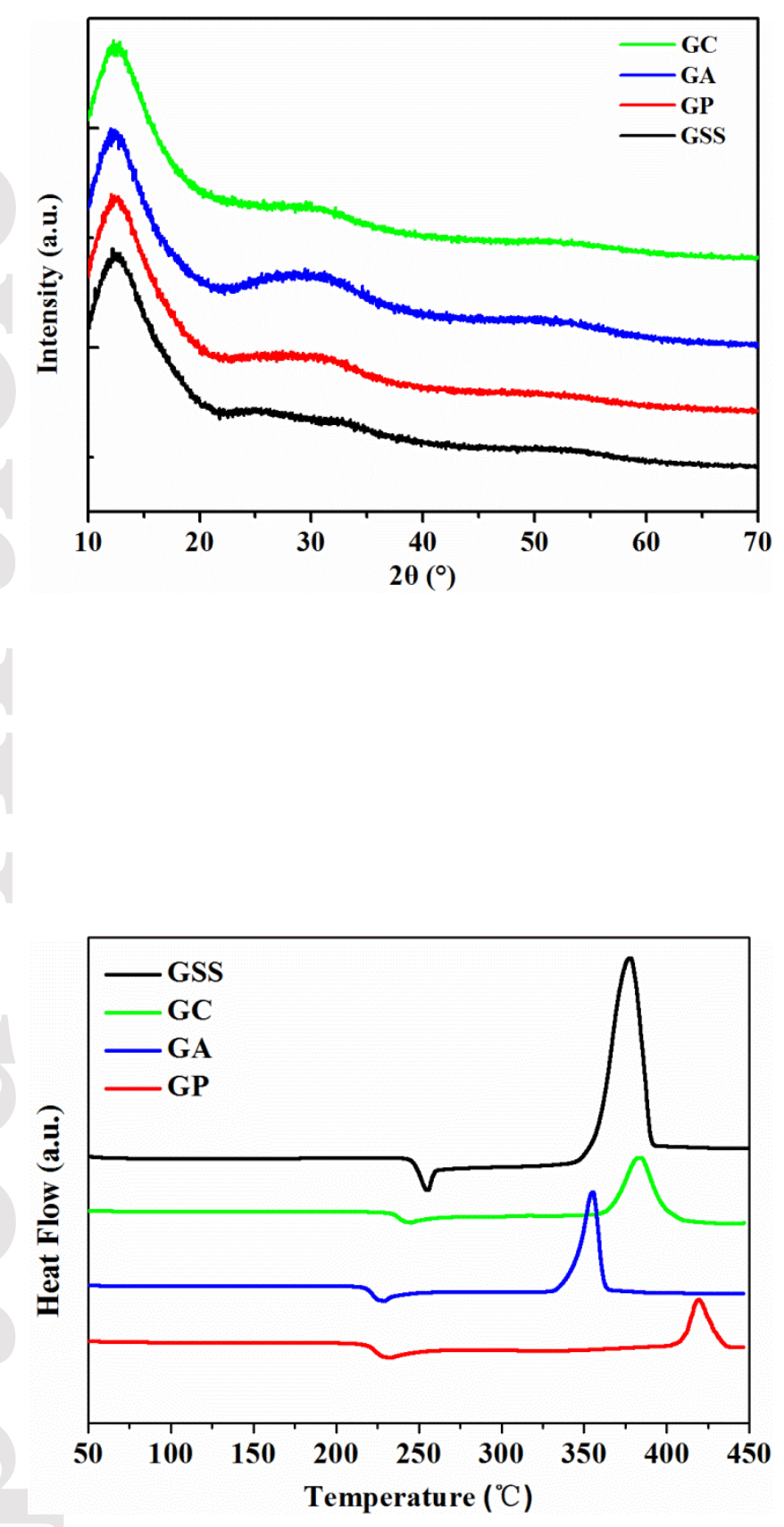

This article is protected by copyright. All rights reserved. 


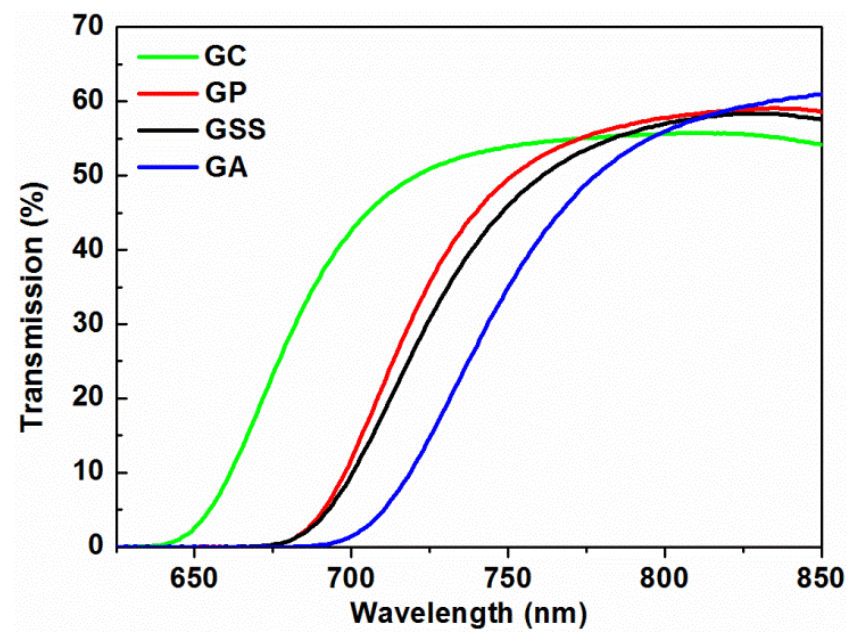

This article is protected by copyright. All rights reserved. 

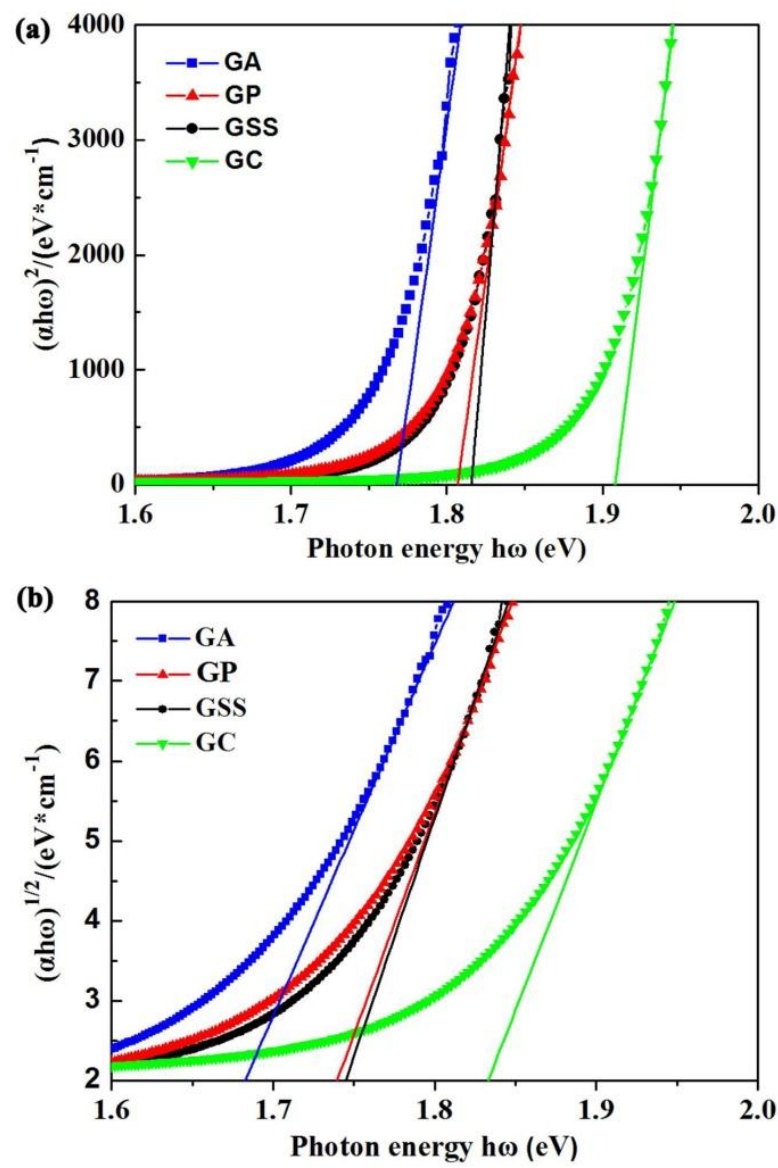

This article is protected by copyright. All rights reserved. 

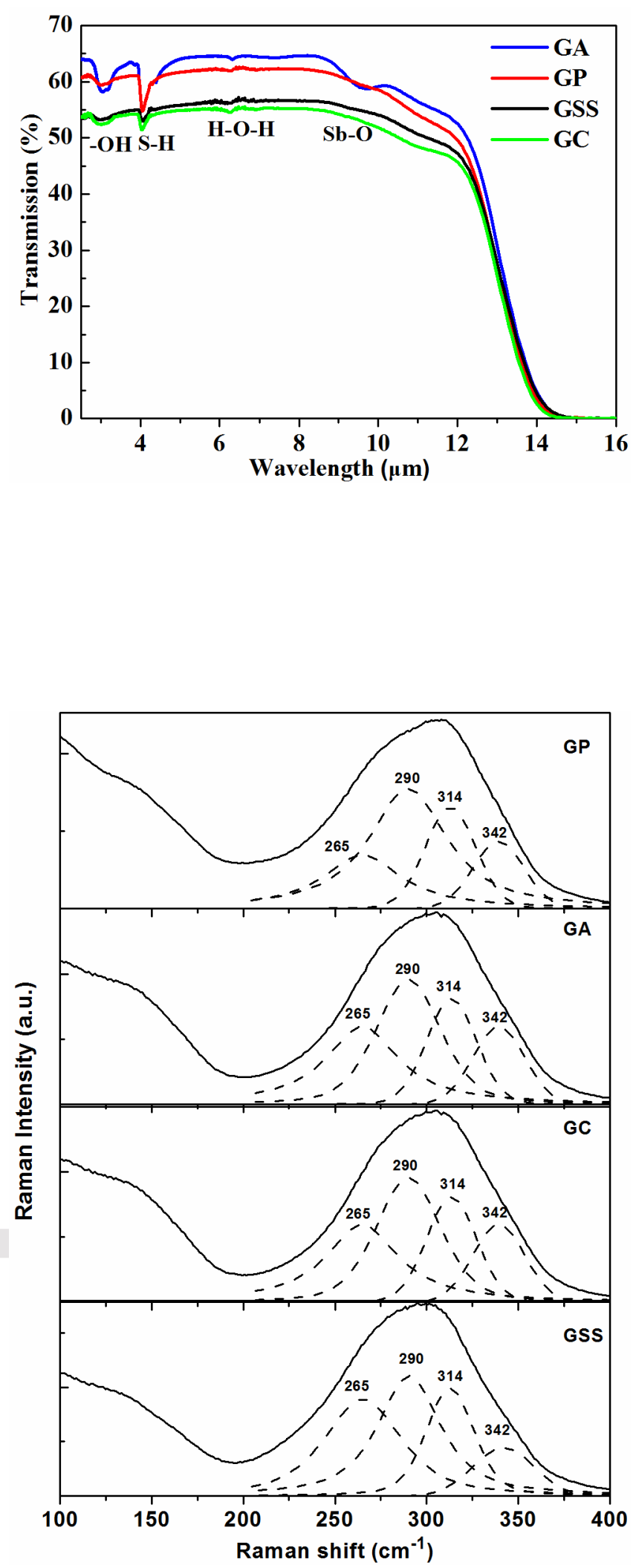

This article is protected by copyright. All rights reserved. 
(a)

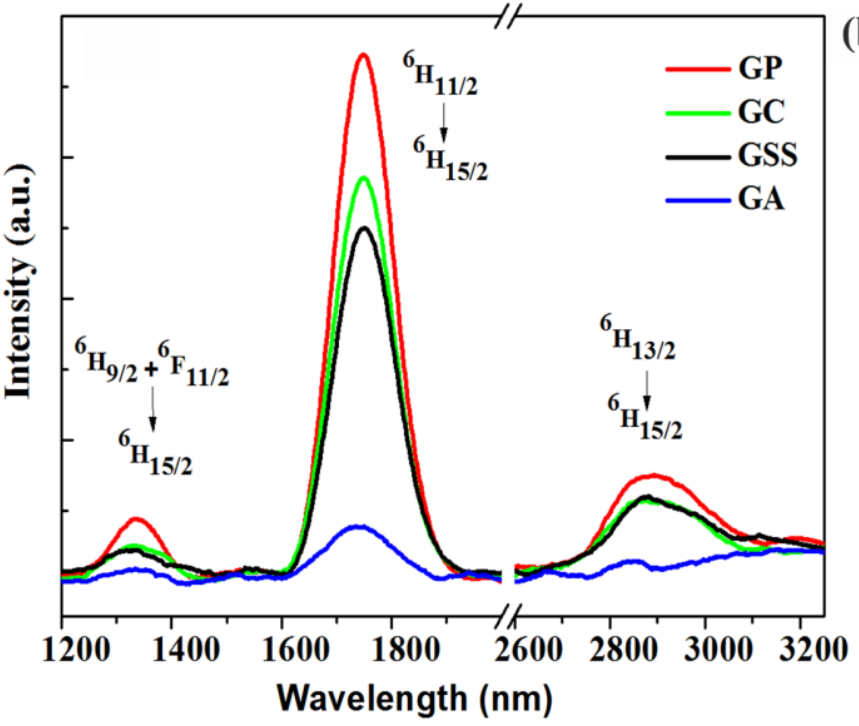

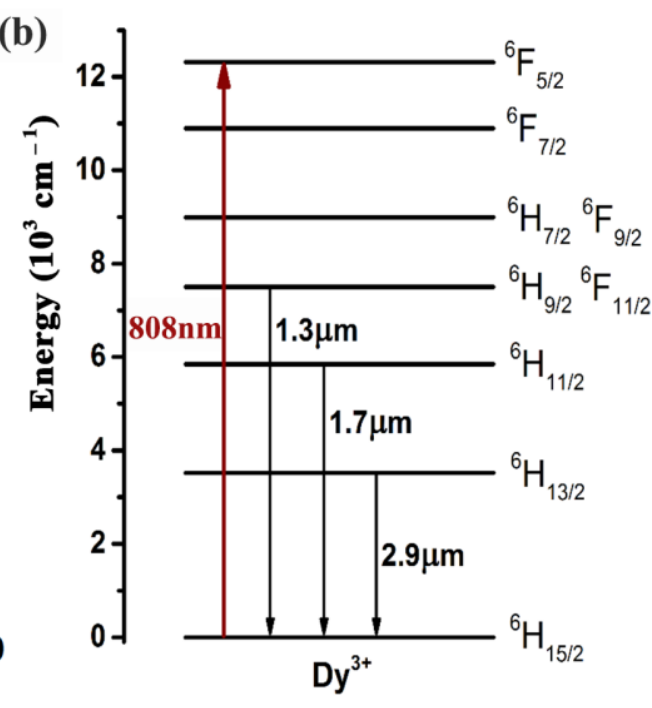

This article is protected by copyright. All rights reserved. 